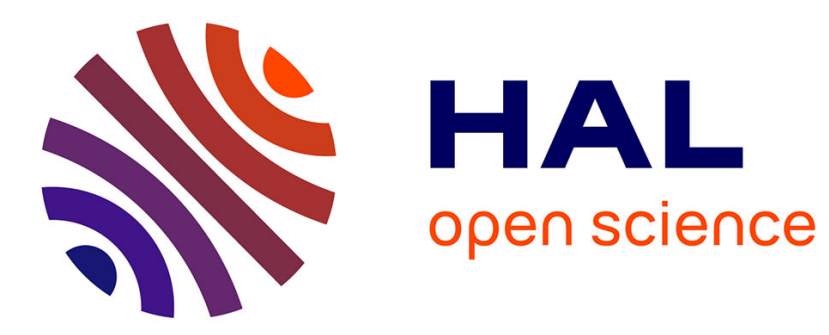

\title{
Small clicks, great effects: Immediate and delayed influence of web sites containing serious games on behavior and attitude
}

Didier Courbet, Marie-Pierre Fourquet-Courbet, Nicolas Guéguen, Robert-Vincent Joule, Severine Halimi, Françoise Bernard

\section{To cite this version:}

Didier Courbet, Marie-Pierre Fourquet-Courbet, Nicolas Guéguen, Robert-Vincent Joule, Severine Halimi, et al.. Small clicks, great effects: Immediate and delayed influence of web sites containing serious games on behavior and attitude. International Journal of Advertising, 2016, 35 (6), pp.949-969. $10.1080 / 02650487.2015 .1082226$. sic_01560526

\section{HAL Id: sic_01560526 \\ https://archivesic.ccsd.cnrs.fr/sic_01560526}

Submitted on 11 Jul 2017

HAL is a multi-disciplinary open access archive for the deposit and dissemination of scientific research documents, whether they are published or not. The documents may come from teaching and research institutions in France or abroad, or from public or private research centers.
L'archive ouverte pluridisciplinaire HAL, est destinée au dépôt et à la diffusion de documents scientifiques de niveau recherche, publiés ou non, émanant des établissements d'enseignement et de recherche français ou étrangers, des laboratoires publics ou privés. 


\title{
Small Clicks, Great Effects \\ The Immediate and Delayed Influence of Websites Containing Serious Games on Behaviour and Attitude
}

\begin{abstract}
The number of websites containing persuasive serious games and advergames has increased over the past several years, but their immediate and delayed effects on behaviour are still not well understood. The present field experiment ( $n=388$, varied socio-professional groups) demonstrates that interactivity linked to this type of website provokes positive effects on immediate behaviour (purchases of energy-saving light bulbs -ESLBs- ) in a "real setting". It further affected the behaviour (installation of ESLBs at home), the memorization of the website's arguments, gains in knowledge, attitude, and other judgments regarding ESLBs, when measured two weeks later. The digital signature of a commitment to perform an expected behaviour via a Web page also provokes positive behavioural effects. This can accumulate through the effects of interactivity. We close with a discussion of the possible psychological processes involved, theoretical and practical implications and limitations as well as new perspectives for advertising and advergames research.
\end{abstract}

\section{(148 words)}

Keywords: interactivity; serious game; advergame; persuasion; environmental communication; website. 


\section{Small Clicks, Great Effects}

\section{The Immediate and Delayed Influence of Websites Containing Serious Games on Behaviour and Attitude}

There has been a growing interest in gamification in digital media in recent years, and the number of websites containing persuasive serious games (SGs) has increased (Vedrashko 2011; Terlutter and Capella 2013 ; An and Kang 2014). Broadly defined, persuasive SGs are computer games specifically designed to change attitudes, beliefs, and behaviour in the areas of business (e.g. advergames), health, safety, and the environment. Wouters, van Nimwegen, van Oostendorp and van der Spek (2013, p. 250) describe computer games as being interactive based on a set of agreed rules and constraints that are directed toward a clear goal that is often set by a challenge. In addition, games provide feedback either as a score or as changes in the game world to enable players to monitor their progress toward the goal.

However, there is little research on the influence of websites containing persuasive SGs on immediate behaviour such as making purchases. Similarly, little is known about their delayed effect several days after the game was played. Questions include: What are the deferred consequences on behaviour, attitudes, and judgments regarding the theme of the game? Are there any gains in knowledge in connection with the theme of the game or in recalling the underlying message of the game? The goal of this research is to identify these effects and gain a better understanding of the processes that underlie persuasion.

\section{Theoretical background}

\section{Effects of serious games, interactivity and persuasive websites}

Several studies have compared the effects of SGs to those of more traditional media. The recent meta-analysis of Wouters et al. (2013) was derived from 39 studies and includes various audiences of different ages (both adults and students) in diverse areas. The results show that the use of SGs leads to better knowledge gains in relation to the game's theme versus other media such as print and websites. Ratan and Ritterfeld (2009) indicate that the knowledge gained through SGs 
persists over the long term — things learned are more ingrained.

However, these studies involve multiple independent variables because they compare the effects of SGs with those of other media. Because both the content and the media change, determining the exact effects of the SGs can be difficult.

It is also interesting to analyse research results that compare the effects on two groups of people-active players and those who only watch the game unfold without actually playing. All those involved are exposed to the same information and the same media. The main difference between the two groups is that only the active players can control the game using their psychomotor skills by means of a computer mouse. Thus, in the context of humanitarian aid, Peng, Lee, and Heeter (2010) have demonstrated that SG players show a greater intent to help needy populations than those who simply observe. Using a health promotion role-playing game and employing social cognitive theory, Peng (2008) demonstrated that the mediated enactive experience afforded by game playing is more effective than the mediated observational experience provided by game watching in influencing self-efficacy. In this study, we used the same methodological principle to obtain the interactive $v s$ non-interactive conditions of the game.

In experiment involving active play, the game conditions are much more interactive for the active participants than those simply watching. Because our focus is on SGs hosted on persuasive websites, two areas of research on the effects of interactivity are of interest - the interactivity of serious computer games and the interactivity of persuasive websites.

First, in the SG field and computer games more broadly, "the interactivity element refers to the player's ability to initiate and receive feedback for actions during the game, whereby such actions influence the course of events that occur during the game" (Blumberg et al. 2013, p. 338). Many studies have investigated the effects of interactivity on players. Interactivity grabs players' attention and commitment and increases the likelihood of learning (Sellers 2006). Interactivity can easily evoke a pleasant feeling of immersion in the game. It lowers the player's awareness of the actual cognitive effort involved in the game (Sherry 2004). Ritterfeld, Cody, and Vorderer (2009) 
established a relationship between the concept of interactivity and the persuasion theory proposed by Petty and Cacioppo (1986). Interactivity enhances elaboration and central processing of the information that is communicated via the SGs. It also encourages the memorization of information and a change in attitude toward the game's theme (see Fourquet-Courbet and Courbet 2014).

Second, in the literature on the effects of persuasive websites, especially those concerned with marketing, the term interactivity is still evolving and needs clarification (Shrum, Lowrey, and Liu 2009; Kim, Spielmann, and McMillan 2012; on the concept of interactivity in general, see Sundar, Kalyanaraman, and Brown 2003; Bucy and Tao 2007). Liu and Shrum's definition (2002, p. 54) of interactivity remains the most common. Namely, that it is "the degree to which two or more communicating parties can act on each other, on the communication medium, and on the message and the degree to which such influences are synchronized." Interactivity has two dimensions. The first dimension considers interactivity as a feature and a structural characteristic of a media or message (e.g. a website, Sicilia, Ruiz, and Munuera 2005). Research into the persuasive effects of this dimension of interactivity provides conflicting results. Some research has indicated a positive effect from interactivity on attitudes towards a website's theme (Sicilia, Ruiz, and Munuera 2005). In contrast, McMillan, Hwang, and Lee (2003) found that attitudes were unfavourable towards a hotel website if it had too many interactive features.

The second dimension looks at how interactivity is perceived by users (Liu 2003). It is a malleable experience affected by structural interactivity. It also varies with personal or situational variables (Kim et al. 2012). Generally speaking, there is no consensus on the different components of perceived interactivity. In the literature directly studying persuasive websites, perceived interactivity is most often seen as consisting of two dimensions (Shrum et al. 2009). The first is active control—a user's ability to participate voluntarily in communication and instrumentally influence it. This construct refers to the extent to which a user feels in control of the interaction experience. The second is two-way communication, which captures the bi-directional flow of information. This refers to the capacity for reciprocal communication between companies and users. 
However, on a theoretical and empirical level, it is difficult to separate the control dimension from the two-way communication dimension (Shrum et al. 2009). Research on the impact of perceived interactivity has demonstrated that it is associated with improved attitudes towards the website/brand as well as with greater intentions to purchase (Kim et al. 2012; van Noort, Voorveld, and van Reijmersdal 2012). In recent models, perceived interactivity is seen as a mediator between structural interactivity and persuasive outcomes (Song and Zinkhan 2008). For example, van Noort et al. (2012) demonstrate that a more structurally interactive website increases the perceived interactivity. Ultimately, interactivity increases the magnitude of the cognitive response, i.e., product-related thoughts. Interactivity improves the attitude toward the brand and increases intention to purchase the advertised product.

Referring to the theory of persuasion proposed by Petty and Cacioppo (1986), Liu and Shrum (2009) developed a dual-process model of interactivity effects in an advertising context. They show that under conditions of low involvement, the mere presence of interactivity serves as a peripheral cue that leads to more positive attitudes toward the brand regardless of the user's ability. Under highinvolvement conditions however, interactivity enhances the processing of the arguments and elicits more positive attitudes toward the brand for experienced users. Inexperience users have less positive attitudes. In general, web-based communication with higher levels of interactivity provides users with greater cognitive development of information, as well as better recall and learning (Tremayne and Dunwoody 2001).

In both the literature on SGs and interactive persuasive websites, the effects have predominantly been measured in terms of attitudes, cognitions, and judgments. This is often immediately after contact. However, the field remains unclear on the persistence of these effects and whether there are any effects on actual behaviour including purchasing behaviour. This is of supreme interest to managers and practitioners. However, to the best of our knowledge, no research has been conducted on these effects. There is also a lack of research into a particular type of serious game called "advergames". Advergames are specifically designed or adapted to promote brands and 
products (Cauberghe and de Pelsmacker 2010). Research has shown the positive effects of advergames on recall, brand recognition, preferences and attitude to the embedded brand (Hernandez and Chapa 2010; Wise et al. 2008; van Reijmersdal et al. 2015). The positive effects on attitudes toward the brand can be observed whether players win or lose at the game (Steffen, Mau, and Schramm-Klein 2013). Likewise, interactivity and attitude toward advergames have significant positive effects on attitude toward the brand, which in turn, positively impacts the purchase intention (Goh and Ping 2014).

The objective of this research is to fill the current gap by focusing, in particular, on the immediate and delayed effects of website interactivity that contains persuasive SGs on behaviours, cognitions, and judgments related to the subject of the game. Another objective of the study is to take an additional step in understanding the influence of interactivity by testing the effects of another feature that we have seen develop recently in websites and persuasive SGs, that is, digitally signing one's name on a commitment form to perform the behaviours promoted in the website.

\section{The behavioural effects of digitally signing a commitment form}

Many applied research studies have shown that having people manually sign a commitment form on paper significantly increases the likelihood that they will do the expected task. For example, Pardini and Katzev (1983) show that people who sign a commitment form to recycle newspapers actually do recycle more newspapers than those who attend an information session on newspaper recycling. Similarly, Pallack and Cummings (1976) demonstrate that people who sign a commitment form on energy conservation save more energy than those who are only subjected to an informational campaign on energy savings. Other authors have obtained similar results including Joule, Bernard, and Halimi-Falkowicz (2008) and Werner et al. (1995). This research was designed to help local agencies select the easiest but most impactful method of encouraging residents to participate in a free curbside-recycling program. They showed that residents who signed a written commitment were more likely to participate (and to participate more than once) than those who learned about the program face-to-face, by telephone, or only from a flyer. 
These results have often been explained using commitment theory (Kiesler 1971). In this context, individuals attributed the act of signing to internal psychological reasons (rather than external). This gives the impression of being strongly connected to the act, which provides a greater incentive to perform the behaviour (Burger 1999). Our goal here was to study whether having played an SG on an website, signing one's name and then giving one's city of residence on a computer form (called "digitally signing" for the rest of the paper) while agreeing to perform a behaviour actually produces the same positive effects on behaviours as manually signing.

\section{Overview of the experiment}

We outline the experiment to better explain the hypotheses. This experiment falls within an energy-saving context and uses websites with persuasive SGs designed to promote the use of energysaving light bulbs (ESLBs). In the experiment, persuasive websites were composed of different elements. First, participants were presented with a short SG including two versions: interactive and non-interactive game conditions. The game consisted of swapping incandescent light bulbs (ILBs) with ESLBs to obtain energy economy in the home. Second, they were given the results of the game indicating the energy and ecology savings achieved due to ESLBs, followed by a persuasive message encouraging the use of ESLBs. Third, they were asked (or not) to digitally sign a commitment form to change at least one ILB for an ESLB in their home within 10 days. The outcome behaviour included ESLB purchases immediately following exposure to the SG. For this reason, viewing occurred just before the subjects entered a large home improvement store. Other measures were performed two weeks later and included changing the light bulbs in homes and memorization of the message, attitudes, judgments, and knowledge gains concerning ESLBs. This period was selected to allow people time to buy and replace the light bulbs.

\section{Hypotheses}

Following Ritterfeld et al. (2009) and in line with Liu and Shrum's (2009) dual-process model, we first made three hypotheses. Research on the effects of SGs (Blumberg et al. 2013) and the effects of the interactivity of persuasive websites (van Noort et al. 2012) have shown overall 
positive results on attitudes toward the objects as well as retention of information and knowledge gains. Thus, we also expect favourable effects on behaviour even at two weeks post-exposure. We will discuss these results to further explain the psychological processes involved.

Hypothesis 1. The interactive game conditions of the persuasive website lead to more ESLB purchases immediately afterwards than do the non-interactive game conditions of the persuasive website. In addition, it is expected that those who are exposed to interactive conditions will buy more light bulbs than those who are not exposed to any website at all.

Hypothesis 2. Two weeks after the exposure-and in relation to the non-interactive conditions of the game - the interactive game conditions promote favourable knowledge gain as well as better retention of the message, attitudes and judgments regarding ESLBs. Furthermore, it is expected that these effects will also be observed in those who are subjected to interactive games versus those who are not exposed to any website.

Hypothesis 3. Two weeks after exposure, it is expected that more ILBs will be replaced by ESLBs in homes in the interactive game conditions in comparison to the non-interactive game conditions. Moreover, it is expected that more light bulb purchases will be observed from those who were subjected to interactive games versus those who were not exposed to any website.

Hypothesis 4. Two weeks later, it is expected that a greater number of ILBs will be replaced by ESLBs in homes in conditions where the website is associated with the digital signature of a commitment form when compared to the website without the option of digital signing.

A further goal is to identify which SG-based website has the greatest impact on changing light bulbs up to two weeks later. Can the effects of the interactive conditions be combined with the effects of the digital signature to achieve the desired behaviour? This managerial objective is important for web designers and designers of persuasive SGs. Indeed, these people are trying to develop the most effective tools possible to influence consumer behaviour. Likewise, can the digital commitment signature by itself, i.e., not associated with a website containing a persuasive SG, induce consumers to change their home light bulbs up to two weeks later? 


\section{Method}

\section{Experimental design}

Four persuasive websites containing a SG were designed based on the same content (a short SG followed by a persuasive message). The only difference between the websites was in the manipulation of the two independent variables. The first independent variable related to the game conditions: interactive (experimental conditions 1 and 2) or non-interactive (experimental conditions 3 and 4). The second independent variable was the presence (conditions 1 and 3) or absence (conditions 2 and 4) of a commitment form to replace one ILB with an ESLB in the home within 10 days requiring a digital signature. The experiment used a between-subjects, 2 (with versus without interactive conditions of the game) X 2 (with versus without digital signing of a commitment form) design. The study also included two control conditions. A fifth website was designed to isolate the effects of the digital signature. It consisted of a "neutral" non-persuasive website with a commitment form for signature (condition 5). Condition 6 had no website page visit and no commitment form.

\section{Materials and pre-tests of materials}

The four experimental websites began with a home page displaying the logo of the French agency for environmental protection and energy management. They each included four stages (see Table 1):

- First stage and "interactivity" independent variable: the short SG. The living room, dining room and kitchen would be visited (see Appendix A). The game consisted of replacing a number of ILBs, given in advance, with ESLBs in each room to achieve the greatest energy savings. The game graphics were created from photographs and were thus highly realistic. There were two time-limited phases. The time remaining was indicated on the screen similar to video games, and this time was the same for all games. In the first phase, the player discovers the room and its lighting and notes several light bulbs. The subject then sees the power of each light bulb when an onscreen moving arrow passes over the bulb. The subject then considers which light 
bulbs to replace to achieve the greatest energy savings, i.e., by replacing the bulbs that consume the most energy. Depending on the rooms, the first phase lasted from 10 to 20 seconds. This was simply a reflection period for the subjects regardless of the SG. Here, the subjects tried cognitively to resolve the problem. They made no changes during this phase. The game was designed so that the subjects could easily find the correct solutions in the allotted time. The second phase began after a message indicating that changes would now be made. These changes were made with a moving arrow on the screen. When the arrow touched a light bulb, the bulb was replaced with an ESLB accompanied by a "click" sound. The "interactivity" variable is manipulated as follows. Under interactive conditions, the subjects moved the arrow with the mouse and clicked to produce the light bulb change. The expected response was replacement of the ten bulbs that consumed the most energy. Under non-interactive conditions, the subjects did not touch the mouse. Rather, they saw a video where the arrow moved on its own and clicked on the appropriate light bulbs.

- Second stage. In this part, the program gave an explanation of the financial and ecological gains related to light bulb changes. These included the energy and financial gains for the household, for a large city, and finally the environmental impact for an entire country (Appendix B). The information and the amount of time it appeared on the screen (30 seconds) were identical for all experimental conditions.

- Third stage. The subjects received a persuasive message with five arguments in favour of ESLBs (Appendix B).

- Fourth stage. In all of the experimental conditions (1 to 4), a written message indicated that the site visit was over and thanked the subjects for their participation. The exposure time to websites containing the SG was the same across all conditions (4 minutes 35 seconds). In the two experimental conditions with a commitment form, a written message indicated that they could also, if they wished, digitally sign a 
commitment form that stated: "I pledge to change at least one incandescent light bulb with an energy-saving light bulb in my home within 10 days." Subjects were prompted to answer yes or no. If they answered yes, they digitally signed the form by writing their first name, last name, and city of residence.

Table 1 here

To create the "neutral" non-persuasive control website with a decorative theme, we used a pre-test to design a site for which the average visit duration was identical to that of the other experimental websites ( 4 minutes and 35 seconds). At the end of the visit to this website, a message indicated that the site visit was over and thanked the subjects for their participation. A written message stated that they could digitally sign a commitment form if they so wished (the same form as in the experimental conditions).

Two pre-tests, one qualitative and one quantitative, were carried out. The qualitative pre-test involved 52 subjects ( $52 \%$ men, $48 \%$ women). First, a concurrent protocol technique was used when subjects viewed the websites (Kuusela and Paul 2000). Subjects consulted one of the websites normally, "as they would do in everyday life," and were asked to say aloud what they thought without self-censorship or further elaboration. Second, after consulting the website, the protocol was followed by a semi-structured interview. The results show that: a) The two experimental SGs incited subjects to adopt a similar cognitive strategy in resolving the same problem-all subjects systematically sought to change the appropriate bulbs within the same problem-solving timeframe. b) All subjects in contact with both SGs found the appropriate bulbs to be changed, and c) The subjects understood the persuasive message and found the materials easy to use.

Even if it seems reasonable to assume that using the computer mouse to play is more interactive than simply watching the game unfold, we wanted to ensure that this interactivity difference actually occurred. We measured the subjects' perceived interactivity when in contact with both sites using a quantitative pre-test. We used Liu's scales (2003) adapted to our particular 
experimental situation. In our situation, the "active control" dimension was the most relevant measurement. The other interactivity dimensions were poorly suited to the equipment. This dimension was measured using the four items of Liu's (2003) interactivity scale adapted to the context of websites containing persuasive SGs. The results (Table 2) confirmed that the game conditions installed by the two persuasive websites were indeed associated with strongly contrasting levels of perceived interactivity.

Table 2 here

\section{Subjects and procedure}

The subjects were all consumers entering a large home improvement store near the city of Aix-en-Provence (140,000 inhabitants) in France. There were 388 subjects including $51 \%$ men and $49 \%$ women with a mean age of 47.6 and of varied socio-professional groups. They were randomly assigned to one of the six conditions.

Subjects were recruited just before entering the store and were asked to evaluate the quality of a new website before its publication online (pretext request for the cover story, conditions 1 to 5). Subjects were to spend a few minutes visiting the site alone in front of a computer screen located in a quiet location just before entering the store. They were asked to look at the site as they "normally" would. To reinforce the cover story subjects were asked to fill out a questionnaire containing five simple questions about the site's ergonomics, in particular the visual comfort and their attitude toward the site. Finally, they were asked their name and telephone number and were told that they might be called later to complete the survey.

Subjects in the second control condition (condition 6, no website visit) were simply recruited to participate in a telephone survey on household habits and practices that was scheduled two weeks later. Their names and telephone numbers were recorded. After thanking them, the subjects entered the store to do whatever they had initially come to do. Two weeks later, the subjects from the six conditions were contacted by phone to answer a questionnaire. 


\section{Measures}

Dependent variables were collected in two phases. The first phase involved direct observation of the subjects from the six conditions in the store without their knowledge in order to record the number of immediate ESLB purchases. The second phase comprised a telephone survey two weeks later in which the subjects were asked to answer a series of questions for a survey about household energy habits. Answers to the following questions were recorded in order:

a) Three general knowledge questions on ESLBs (multiple-choice items concerning energy consumption, minimum duration of use before achieving cost savings, and the product life of an ESLB). One point was assigned for each correct answer.

b) Three specific knowledge questions on ESLBs (multiple-choice items concerning three types of potential ecological and financial gains achieved by replacing ten ILBs with ten ESLBs in the home). One point was assigned for each correct answer.

The correct answers to the general and specific knowledge questions could all be found on the websites used in the experimental conditions. While the correct answers to the general knowledge questions could also be found outside the experimental material (e.g., in the press), the answers to the specific knowledge questions could only be found by memorizing the gains after playing (memorization of argument).

c) The use of ESLBs contributes to respect for the planet (Likert scale with agreement ranging from 0 to 10$)$.

d) The necessity of telling others about the utility of ESLBs (proselytizing) (Likert scale: 0 to 10$)$.

e) Attitude toward ESLBs (Likert scale: 0 to 10).

f) The utility of ESLBs (Likert scale: 0 to 10 ).

g) The number of ILBs actually replaced by ESLBs in the home over the past two weeks. 
At the end of the survey, respondents were asked to answer some personal identification questions. Once this was done, the results showed similar effects for all four items (question c) to f)). These four were aggregated into a single item entitled "judgments of ESLBs" (Cronbach's alpha for the four items $=0.85$; Table 3 ).

Table 3 here

\section{Results}

The results (Table 4) were processed using four statistical analyses. First, log-linear analyses and chi-square tests were performed to analyse the results regarding immediate purchases and replacement of home light bulbs after two weeks. For the dependent variables measured by Likert scales and knowledge tests, ANOVA was used based on the 2 X 2 experimental design with analyses of the main effects and interactions. Student's t-tests were used for pairwise comparisons of conditional means.

Table 4 here

\section{Results for immediate purchases (hypothesis 1)}

A three-way ( 2 interactive conditions $\mathrm{X} 2$ signature of the commitment form $\mathrm{X} 2$ purchases) log-linear analysis was performed. Backward elimination produced a model that included: i) the interaction effects of interactive conditions and purchases, and ii) the interaction effect of purchases and signature of the commitment form. The final model had a likelihood ratio, $\chi^{2}(2)=2.93, p=$ 0.23 , indicating a good fit between the observed frequencies and the expected frequencies generated by the model. Subjects assigned to interactive conditions of the game purchased more ESLBs immediately after exposure than subjects in non-interactive conditions $\left(16.1 \%\right.$ versus $6 \%, \chi^{2}(1)=$ 5.99, $\mathrm{p}=0.01$, Cramer's $\varphi=0.16$ ). Subjects assigned to interactive conditions also bought more ESLBs than subjects who did not visit a website (condition 6): $16.1 \%$ versus $2.1 \%, \chi^{2}(1)=6.12$, p $=0.01, \varphi=0.20$. Overall, subjects in condition 2 (interactive conditions, no signature) bought the 
greatest number of ESLBs. Thus, hypothesis 1 is confirmed.

It should be noted that versus subjects in control condition 6 (no website visit), the subjects in control condition 5 (neutral site with signature) bought more ESLBs $\left(15.1 \%\right.$ versus $2.1 \%, \chi^{2}(1)=$ 5.11, $\mathrm{p}=0.02, \varphi=0.23$ ). Digitally signing a commitment form had positive effects on immediate purchases.

\section{Results for measures taken two weeks after exposure (hypothesis 2)}

The ANOVA revealed a significant main effect for the interactive conditions of the game, indicating that the subjects placed in the interactive conditions obtained better scores than the subjects assigned to the non-interactive conditions for argument memorization $(F(1,190)=29.01, p$ $\left.<.001, \eta^{2}=0.13\right)$, general knowledge concerning $\operatorname{ESLBs}\left(F(1,190)=32.09, \mathrm{p}<0.001, \eta^{2}=0.15\right)$, and judgments of ESLBs $\left(F(1,188)=48.37, \mathrm{p}<0.001, \eta^{2}=0.20\right)$.

Subjects assigned to interactive conditions obtained better scores than subjects in control condition 5 (neutral site with signature) for argument memorization $(\mathrm{t}(122)=8.18, \mathrm{p}<0.001, d=$ 1.63), general knowledge concerning ESLBs $(\mathrm{t}(122)=3.74, \mathrm{p}<0.001, d=0.75)$, and judgments of ESLBs $(\mathrm{t}(121)=3.31, \mathrm{p}=0.001, d=0.67)$.

Subjects assigned to interactive conditions had better scores than subjects assigned to condition 6 (no website visit) for argument memorization $(\mathrm{t}(133)=8.83, \mathrm{p}<0.001, d=1.61$ ), general knowledge concerning ESLBs $(\mathrm{t}(133)=4.98, \mathrm{p}<0.001, d=0.92)$, and judgments of ESLBs $(\mathrm{t}(133)=8.42, \mathrm{p}<0.001, d=1.54)$.

These findings confirmed hypothesis 2 . Furthermore, the neutral non-persuasive website with signature (control condition 5) had a positive effect on judgments. Thus, versus control condition 6 (no website visit), the subjects in condition 5 had better judgments of ESLBs $(t(81)=3.79$, p < 0.001, $d=0$.85). Digitally signing a commitment form affected judgments regarding ESLBs.

\section{Actual replacements two weeks later (hypothesis 3)}

A three-way ( 2 interactive conditions $\mathrm{X} 2$ signature of the commitment form $\mathrm{X} 2$ replacements) log-linear analysis was performed. Backward elimination produced a model that 
included, i) the interaction effect of signature of the commitment form and replacement, and ii) the interaction effect of interactive conditions and replacement. The final model had a likelihood ratio $\chi^{2}(2)=1.32, p=0.52$, which indicated a good fit between the observed frequencies and the expected frequencies generated by the model. Subjects assigned to interactive conditions replaced more ESLBs than either subjects in non-interactive game conditions (Table 5) or subjects who did not visit a site (condition 6). This confirmed hypothesis 3 .

\section{Table 5 here}

Subjects who signed a commitment form replaced more ILBs with ESLBs in their homes than subjects assigned to conditions without commitment form signature $\left(86.2 \%\right.$ versus $37.3 \%, \chi^{2}$ $(1)=45.6, p<0.001, \varphi=0.49)$. The results demonstrate that signing has a strong effect on bulb changing. Hypothesis 4 is confirmed.

We next analysed various other effects. We found that signing the commitment form actually had a stronger effect on bulb changing than interactivity (Table 5). There was a positive interaction between signing the commitment form and the interactivity. Indeed, the effects of these two variables can be combined - the most effective website combined a commitment signature and interactivity (condition 1; see Table 6).

\section{Table 6 here}

More generally, when compared to subjects assigned to control condition 6 (no website visit), subjects in conditions 1 through 5 replaced more ILBs with ESLBs (all p < 0.001, see Table 6). All effects are relatively strong because the Cramer's $\varphi$ values are greater than or equal to 0.50 . It is interesting to note that subjects assigned to condition 5 (neutral website with signature) replaced more bulbs than subjects in control condition 6 (no website visit) $(\mathrm{p}<0.001, \varphi=0.50)$. This shows that signing the commitment form alone without the persuasive message leads to changing home light bulbs two weeks later. 


\section{Discussion and conclusion}

Conducted among subjects of various ages and socio-professional groups, the present field experiment makes three contributions, both theoretical and practical. The first theoretical and practical contribution consists of highlighting the effects of websites containing persuasive SGs on actual behaviour. This research is the first in the literature to demonstrate that these websites induce positive effects on immediate behaviours as well as behaviour within a two-week period. The results demonstrate that the persuasive website that incorporated interactive game conditions leads to more immediate purchasing of ESLBs than the same site with non-interactive game conditions. It is important to note that the effects were demonstrated on behaviours that have a true costfinancial costs in purchasing the bulb and time costs in the installation. Affecting buying behaviour is one of the main aims of advertising. This research makes an important contribution to advertising research because, until now, the latter was restricted to showing the effects of advergames on cognitive and attitudinal components with regard to the product or brand (Steffen, Mau, and Schramm-Klein 2013; Goh and Ping 2014; van Reijmersdal al. 2015). This research extends to the effects of advergames to actual buying behaviour and product usage.

Two weeks after contact with the websites, in comparison to the non-interactive game conditions, the interactive conditions led to improved memorization of message arguments and better general knowledge concerning ESLBs. Furthermore, the interactive conditions produced greater effects on attitudes and judgments favourable to ESLB. This included an effect on players proselytizing as the interactive conditions predisposed players to tell others about ESLBs. This result is a second theoretical and practical contribution. Research into advergames has shown that they have positive effects on memorisation and attitude towards the product or brand immediately after exposure (Wise et al. 2008; Hernandez and Chapa 2010; Steffen, Mau, and Schramm-Klein 2013; Goh and Ping 2014; van Reijmersdal et al. 2015). However, consumers rarely make a purchase immediately after playing. The purchase usually occurs after a certain amount of time has passed (several days at the least). To increase the external validity of the advertising research, it is 
important to show that these effects remain in the memory for longer periods of time to influence later decision-making. By gaining external validity, this research shows that the effects on product knowledge as well as memorisation of the message's arguments, attitude, and judgments relating to the brand are still in the memory two weeks after contact. Further research is needed to gain a greater understanding of the processes involved in this decision-making and memory retention because these are many and varied. First, the interactive conditions of the games appear to increase the likelihood that the player will devote more cognitive resources to processing the persuasive information that follows. This facilitates central processing (van Noort et al. 2012), argument memorization, and more generally, persuasion (Petty and Cacioppo 1986). These results are compatible with Liu and Shrum's (2009) dual-process model.

Second, regarding the memorization of the arguments, other processes could also be involved. The virtual environment's resemblance to the real environment, the contextualization of information, and the fact that the player enjoys a positive experience, appear to favour the storage of information in autobiographical and episodic memory (Conway and Pleydell-Pearce 2000). The model proposed by Tulving (2002) postulates that following a process of abstraction and semantic generalization, storage in this type of memory also promotes memorization of general information concerning experience-related themes in semantic memory. More general information is held in semantic memory. In addition, the crossing of sensory registers and multiplication of different encoding schemes facilitates the storage of information-particularly persuasive information-in other types of memory (Tulving 1995) including procedural memory. This last type of memory could also be solicited because interactivity is associated with the realization of psychomotor actions with the mouse.

Third, although it is highly likely that memorization of the arguments occurred upon contact with the sites, other processes could explain some of the other effects. Indeed, it is possible that the attitudes, judgments, and the knowledge gain occurred after the light bulbs were purchased and installed in the home. 
While all of the persuasive websites we tested had had positive effects on bulb replacement two weeks later, the size of the effects varies depending on the game version. The subjects in the interactive game conditions had replaced more light bulbs than subjects in the non-interactive game conditions. More ILBs were replaced when subjects signed a digital commitment versus a website that did not use a digital signature. The persuasive effects of interactivity and digitally signing of a commitment form are cumulative. The effect of digitally signing a commitment form appears to be stronger than the effect of interactivity on the actual replacement of bulbs up to two weeks later. This is the third theoretical and practical contribution of the study.

The processes involved can be explained by commitment theory (Kiesler 1971). When players voluntarily sign a commitment form, they will more easily attribute the act of signing to internal psychological reasons. This gives them a strong sense of connection to their act and further encourages them to perform the behaviour to which they have committed (Joule and Beauvois 2009; Girandola and Joule 2012). Thus, recording one's name and city of residence on a commitment form in a digital manner using the keyboard produces positive effects on behaviours in the same way that hand signing a paper commitment form does (Werner et al. 1995; Pallack and Cummings 1976).

Practitioners (advertisers, advertising agencies, game developers, etc.) may be interested in developing further uses of this persuasive technique. Indeed, this simple technique influences actual behaviour - this is the key aim of advertising. Most work on the effects of advertising and marketing communication focuses on the modification of cognitive and attitudinal components among consumers. Yet while messages may succeed in changing a person's attitude, it does not necessarily imply that their behaviours will similarly change (Glasman and Albarracin 2006). The latter are of course much harder to change. Nevertheless, digitally signing a commitment to perform the behaviour would offer advertisers a more effective technique. Nevertheless, further research is clearly needed to understand the psychological processes underlying these effects. 
This study has some limitations. First, in terms of methodology, the initial conditions of the dependent variables (attitudes, knowledge, etc. regarding ESLBs) have not yet been measured. If we had done such measurements just before or just after playing the serious games, this would have oriented the attention of the subjects on the product and would have changed the purchasing behaviours. That is why we have first chosen to work with two control conditions that ensure that the effects do indeed come from the websites. Second, the subjects were randomly assigned to different experimental and control conditions to control prior knowledge and attitudes and ensure proper internal validity. In addition, the positive influence of interactivity on the memorisation of arguments confirms that the effects could not be explained by the subjects' prior knowledge.

Third, while ESLB buying behaviours were actually observed in the store, the number of ILBs replaced by ESLBs two weeks later in the homes was measured based only on subjects' statements. It was not possible to definitely know whether these statements were true. Finally, even if the socio-professional groups, ages and sexes of the subjects were diverse, the results are limited to the type of product, the store, the website and the SG used in the experiment.

More generally, consumer involvement in the theme of environmental protection and in the product category (ESLBs) is rather strong and it is likely that the results of this experiment may apply especially to high-involvement goods or public service ads. In future research, it would be helpful to extend this research to other products (including low-involvement goods) and other stores including other SGs.

There are numerous new prospects for this research. First, it would be interesting to further increase the observation period for cognitive, attitudinal and behavioural effects as in the experiment conducted in the field of e-advertising (Courbet et al. 2014). Here, effects are observed three months after contact although the subjects have no recollection of being exposed to the advertising. Second, it would be interesting to evaluate the effects of different levels of interactivity (not just its absence or presence) as well as the difficulty of the game on behaviour immediately and after a certain time (see Herrewijn and Poels 2013 in the context of in-game advertising). 
Similarly, it would be very useful to go a step further and understand the effects of the various information items recorded by the subjects on the commitment form. Third, it would be interesting to understand the possible interactions between interactivity and the commitment form. This could be extended to include positive emotions experienced during the game, involvement with the game and involvement with the product. Similarly, given the growing number of studies on the effects of marketing communication on implicit attitudes (Courbet and Fourquet-Courbet 2014), it would be appropriate to further investigate the influences on implicit attitudes towards the game or brand theme (Waiguny, Nelson, and Marko 2013). Fourth, regarding communication tools, it would be interesting to know whether these effects can also be observed with advergames containing brands. Future research could also compare the effects of the game when played on desktop computers versus its effects when played on mobile devices (see Lin 2014 in the context of in-game advertising).

\section{References}

An, S. and Kang, H. (2014) 'Advertising or games? Advergames on the internet gaming sites targeting children', International Journal of Advertising, 33(3), pp. 509-532.

Blumberg, F.C., Almonte, D.E., Anthony, J.S., and Hashimoto, N. (2013) 'Serious Games: What are they? What do they do? Why should we play them?', in Oxford Handbook of Media Psychology, (Ed.) Dill, K., pp. 334 - 351. New York: Oxford University Press.

Bucy, E. P. and Tao, C.-C. (2007) 'The Mediated Moderation Model of Interactivity', Media Psychology, 9(3), pp. 647-672. 
Burger, J. M. (1999) 'The Foot-in-the-Door Compliance Procedure: A Multiple-Process Analysis and Review', Personality and Social Psychology Review, 3(4), pp. 303 -325.

Cauberghe, V. and De Pelsmacker P. (2010) 'Advergames: The impact of brand prominence and game repetition on brand responses', Journal of Advertising, 39(1), pp. 5-18.

Conway, M. A. and Pleydell-Pearce, C. W. (2000) 'The construction of autobiographical memories in the self-memory system', Psychological Review, 107(2), pp. 261-288.

Courbet, D., Fourquet-Courbet, M.-P., Kazan, R. and Intartaglia J. (2014) 'The Long-term Effects of E-advertising. The Influence of Internet Pop-ups Viewed at a Low Level of Attention in Implicit Memory', Journal of Computer-Mediated Communication, 19 (2), pp. 274-293.

Courbet, D. and Fourquet-Courbet, M.-P. (2014) 'Non-conscious Effects of Marketing Communication and Implicit Attitude Change: State of Research and New Perspectives', International Journal of Journalism and Mass Communication, 1(103), Doi: 10.15344/23492635/2014/103.

Fourquet-Courbet, M.-P. and Courbet, D. (2014) 'Les serious games, dispositifs numériques de médiation : Processus socio-cognitifs et affectifs dans les usages et les effets sur les publics (Serious games, digital dispositives on mediation: sociocognitive and emotional processes in the uses and effects on the public)', Culture et Musées, 22, pp. 165-190.

Girandola, F. and Joule, R.-V. (2012) 'La communication engageante : aspects théoriques, résultats et perspectives', L’Année psychologique, 112(01), pp. 115-143.

Glasman, L. R. and Albarracin, D. (2006) 'Forming attitudes that predict behavior: A MetaAnalysis of the attitude-behavior relation', Psychological Bulletin, 132(5), pp. 778-822.

Goh, K.-Y. and Ping, J. W. (2014) 'Engaging Consumers with Advergames: An Experimental Evaluation of Interactivity, Fit and Expectancy', Journal of the Association for Information Systems, 15(7), Art. 2. 
Hernandez, M. D. and Chapa, S. (2010) 'Adolescents, advergames and snack foods: effects of positive affect and experience on memory and choice', Journal of Marketing Communications, 16(1-2), pp. 59-68.

Herrewijn, L. and Poels, K. (2013) 'Putting brands into play: how game difficulty and player experiences influence the effectiveness of in-game advertising'. International Journal of Advertising, 32(1), pp. 17-44.

Joule, R. and Beauvois, J. (2009) La soumission librement consentie : comment amener les gens à faire librement ce qu'ils doivent faire? Paris: Presses Universitaires de France.

Joule, R., Bernard, F. and Halimi-Falkowicz, S. (2008) 'Promoting ecocitizenship: in favor of binding communication', International Scientific Journal for Alternative Energy and Ecology, 6(62), pp. 214-218.

Kiesler, C. A. (1971) The psychology of commitment: experiments linking behavior to belief. New York: Academic Press.

Kim, J., Spielmann, N. and McMillan, S. J. (2012) 'Experience effects on interactivity: Functions, processes, and perceptions', Journal of Business Research, 65(11), pp. 1543-1550.

Kuusela, H. and Paul, P. (2000) 'A comparison of concurrent and retrospective verbal protocol analysis', American Journal of Psychology, 113(3), pp. 387-404.

Lin, H. (2013) 'The effect of product placement on persuasion for mobile phone games', International Journal of Advertising, 33(1), pp. 37-60

Liu, Y. and Shrum, L. J. (2002) 'What Is Interactivity and Is It Always Such a Good Thing? Implications of Definition, Person, and Situation for the Influence of Interactivity on Advertising Effectiveness', Journal of Advertising, 31(4), pp. 53-64.

Liu, Y. and Shrum, L. J. (2009) 'A Dual-Process Model of Interactivity Effects', Journal of Advertising, 38(2), pp. 53-68.

Liu, Y. (2003) 'Developing a Scale to Measure the Interactivity of Websites', Journal of Advertising Research, 43(02), pp. 207-216. 
McMillan, S.J. Hwang, J.-S., and Lee, G. (2003) 'Effects of Structural and Perceptual Factors on Attitudes toward the Website', Journal of Advertising Research, 43(4), 400-409.

Pallack, M. S and Cummings, W. (1976) 'Commitment and voluntary energy conservation', Personality and Social Psychology Bulletin, 2(1), pp. 27-30.

Pardini, A. U. and Katzev, R. D. (1983) 'The effect of strength of commitment on newspaper recycling', Journal of Environmental Systems, 13(3), pp. 245-254.

Peng, W. (2008) 'The mediational role of identification in the relationship between experience mode and self-efficacy: Enactive role-playing versus passive observation', CyberPsychology and Behavior, 11(6), pp. 349-652.

Peng, W., Lee, M. and Heeter, C. (2010) 'The Effects of a Serious Game on Role-Taking and Willingness to Help', Journal of Communication, 60(4), pp. 723-742.

Petty, R. E. and Cacioppo, J. T. (1986) Communication and persuasion: Central and peripheral routes to attitude change. New York: Springer-Verlag.

Ratan, R. and Ritterfeld, U. (2009) 'Towards a Psychological Classification of Serious Games', in Serious Games: Mechanisms and Effects, (Eds) Ritterfeld, U., Cody, M. and Vorderer P., pp. 10-24. Mahwah, NJ: Routledge/LEA.

Ritterfeld, U., Cody, M. J. and Vorderer, P. (Eds.) (2009) Serious Games: Mechanisms and Effects. New York: Routledge.

Sellers, M. (2006) 'Designing the Experience of Interactive Play’, in Playing video games: Motives, responses, and consequences, (Eds) Vorderer, P. and Bryant, J., pp. 9-22, Mahwah, NJ: Lawrence Erlbaum.

Sherry, J. L. (2004) 'Flow and media enjoyment', Communication Theory, 14, pp. 328-347.

Shrum, L. J., Lowrey, T. and Liu, Y. (2009) 'Emerging Issues in Advertising Research', in The SAGE Handbook of Media Processes and Effects, (Eds.) Oliver M.B. and R. Nabi, R, pp. 299-312. Thousand Oaks, CA: Sage Publications.

Sicilia, M., Ruiz, S. and Munuera, J.L (2005) 'Effects of Interactivity in a Web Site: The 
Moderating Effect of Need for Cognition', Journal of Advertising, 34 (3), pp. 31-44.

Song, J.H. and Zinkhan, G.M. (2008) ‘Determinants of Perceived Website Interactivity’, Journal of Marketing, 72 (2), pp. 99-113.

Steffen, C., Mau, G. and Schramm-Klein, H. (2013) 'Who Is the Loser When I Lose the Game? Does Losing an Advergame Have a Negative Impact on the Perception of the Brand?', Journal of Advertising, 42 (2-3), pp. 183-195.

Sundar, S. S., Kalyanaraman, S., and Brown, J. (2003) 'Explicating Website Interactivity: Impression Formation Effects in Political Campaign Sites', Communication Research, 30(1), pp. 30-59.

Terlutter, R. and Capella, M. L. (2013) 'The Gamification of Advertising: Analysis and Research Directions of In-Game Advertising, Advergames, and Advertising in Social Network Games', Journal of Advertising, 42(2-3), pp. 95-112.

Tremayne, M. and Dunwoody, S. (2001) 'Interactivity, Information Processing, and Learning on the World Wide Web', Science Communication, 23(2), pp. 111-134.

Tulving, E. (1995) 'Organization of memory: Quo vadis', in The cognitive neurosciences, (Ed.) Gazzaniga M., pp. 839-847. Cambridge: Mass: MIT press.

Tulving, E. (2002) 'Episodic Memory: From Mind to Brain', Annual review of psychology, 53(1), pp. $1-25$.

Van Noort, G., Voorveld, H.A.M. and van Reijmersdal, E.A (2012) 'Interactivity In Brand Websites: Cognitive, Affective, and Behavioral Responses Explained By Consumers' Online Flow Experience', Journal of Interactive Marketing, 26(4), pp. 223-234.

Van Reijmersdal, E. A, Lammers, N, Rozendaal, E. and Buijzen, M. (2015) 'Disclosing the Persuasive Nature of Advergames: Moderation Effects of Mood on Brand Responses via Persuasion Knowledge', International Journal of Advertising, 34(1), pp 70-84.

Vedrashko, I. (2011) 'Game-Based Marketing: Inspire Customer Loyalty Through Rewards, Challenges, and Contests', International Journal of Advertising, 30(1), pp. 189-190. 
Waiguny, M. K. J., Nelson, M. R. and Marko, B. (2013) 'How Advergame Content Influences Explicit and Implicit Brand Attitudes: When Violence Spills Over', Journal of Advertising, 42 (2-3), pp. 155-169.

Werner, C. M., Turner, J., Shipman, K., Shawn Twitchell, F., Dickson, B. R., Bruschke, G. V. and Von Bismarck, W. B. (1995) 'Commitment, Behavior, and Attitude Change: An Analysis OfoRecycling', Journal of Environmental Psychology, 15(3), pp. 197-208.

Wise, K., Bolls, P. D., Kim, H., Venkataraman, A. and Meyer, R. (2008) 'Enjoyment of Advergames and Brand Attitudes: The Impact of Thematic Relevance', Journal of Interactive Advertising, 9 (1), pp. 1-11.

Wouters, P., Van Nimwegen, C., Van Oostendorp, H. and Van der Spek, E. G. (2013) 'A MetaAnalysis of the Cognitive and Motivational Effects of Serious Games', Journal of Educational Psychology, 105, 2, pp. 249-265. 